\title{
Soroprevalência de anticorpos anti-Neospora caninum em cães da cidade de Cuiabá, Estado de Mato Grosso
}

\section{Seroprevalence of anti-Neospora caninum antibodies in dogs from Cuiaba city, Mato Grosso State}

\author{
Andréia Lima Tomé Melo; Glaucenyra Cecília Pinheiro da Silva ${ }^{1}$; \\ Daniel Moura de Aguiar $^{2 *}$
}

\begin{abstract}
Resumo
O presente avaliou a prevalência de anticorpos anti-Neospora caninum em 406 cães da cidade de Cuiabá, Estado de Mato Grosso pela Reação de Imunofluorescência Indireta (RIFI) com ponto de corte na diluição inicial de 1:50. Foram observados 27 cães positivos (6,6\%, IC95\% 4,6-9,6\%) com títulos variando entre 50 e 1600. Segundo a raça estudada, a maior frequência foi observada para cães Pit Bull onde 4 cães $(16,7 \%)$ foram positivos $(\mathrm{P}=0,06)$. Não houve diferença significativa entre a soropositividade e a faixa etárias dos cães. Dos cães positivos, 10 eram fêmeas $(5,6 \%)$ e $17(7,5)$ eram machos $(\mathrm{P}>0.05), 7(9,0 \%)$ se alimentavam de ração e $20(6,1 \%)$ de alimentação caseira. Variáveis relacionadas ao ambiente demonstraram que dentre os positivos $15(7,5)$ tinham acesso a rua, $21(7,5 \%)$ residiam em casa próximas a terrenos baldios, $20(6,2 \%)$ em casas muradas e $20(6,8)$ em casas que apresentavam roedores no quintal. Nenhuma das variáveis apresentou associação significativa $(P>0,05)$. Os resultados do presente estudo demonstram uma baixa prevalência de anticorpos anti- $N$. caninum na população canina da cidade de Cuiabá e as diversas variáveis estudadas não se apresentaram associadas à infecção. Ressalta-se a menor prevalência de anticorpos anti- $N$. caninum nas áreas urbanas do Brasil. Palavras-chave: Neospora caninum, cão, anticorpos, prevalência, Cuiabá
\end{abstract}

\begin{abstract}
The present study evaluated the prevalence of anti- Neospora caninum antibodies in 406 dogs from Cuiabá city, Mato Grosso State by means Immunofluorescence Assay (IFA) with cut-off at the initial dilution of 1:50. Twenty seven dogs were positive (6.6\%, 95\% CI\%: 4.6-9.6\%) with titers of antibodies ranging between 50 and 1600 . According to the breed, Pit Bull dogs were the most frequent where 4 dogs $(16.7 \%)$ were positive $(\mathrm{P}=0.06)$. There was no difference between positivity and age of dogs. From the positive dogs, 10 were females $(5.6 \%)$ and 17 were males $(7.5 \%), 7$ dogs $(9.0 \%)$ fed commercial ration and $20(6.1 \%)$ homemade food $(\mathrm{P}>0.05)$. Environmental variables showed that 15 positive dogs $(7.5 \%)$ had access to the street, 21 positive dogs $(7.5 \%)$ lived near to the wasteland, $20(6.2 \%)$ lived in walled house and $20(6.8 \%)$ had contact with rodents in house backyard. None of environmental variables had significant associations $(\mathrm{P}<0.05)$. The results of the present study demonstrate a low prevalence of anti- $N$. caninum antibodies in canine population from Cuiabá city and the analyzed variable did not presented association for infection. The study noteworthy the lower prevalence of anti- $N$. caninum antibodies in urban area from Brazil.

Key words: Neospora caninum, dog, antibodies, prevalence, Cuiabá
\end{abstract}

\footnotetext{
${ }^{1}$ Mestranda(s) do Programa de Pós-Graduação em Ciências Veterinárias da Universidade Federal de Mato Grosso, UFMT, Cuiabá, MT. E-mail: andreialtm@gmail.com; glaucenyracecilia@hotmail.com

${ }^{2}$ Prof. da Faculdade de Agronomia, Medicina Veterinária e Zootecnia da UFMT, Cuiabá, MT. E-mail: danmoura@ufmt.br

*Autor para correspondência
} 


\section{Introdução}

Neospora caninum é um protozoário Apicomplexa responsável por causar abortamentos em bovinos e doença neuromuscular em cães neonatos (DUBEY et al., 2007a). Cães domésticos (Canis familiaris; MCALLISTER et al., 1998), coiotes (Canis latrans; GONDIM et al., 2004) e dingos (Canis lupus dingo; KING et al., 2010) são apontados como hospedeiros definitivos do agente, em virtude da eliminação de oocistos nas fezes. Estudos demonstram que os três estágios infectantes (taquizoítos, bradizoítos e oocistos) deste protozoário estão envolvidos no processo de transmissão. Em ruminantes a infecção ocorre pela ingestão de alimento ou água contaminados com oocistos esporulados e pela via transplacentária envolvendo taquizoítos; enquanto que nos canídeos a transmissão também pode ocorrer pela ingestão de tecidos contendo bradizoítos (DUBEY; SCHARES; ORTEGA-MORA, 2007a).

Em relação às manifestações clínicas de neosporose, cães de qualquer idade podem desenvolver a doença (DUBEY; SCHARES, 2011). Entretanto os casos mais graves ocorrem mais frequentemente em cães jovens, congenitamente infectados, os quais, em sua maioria, nascem assintomáticos e cerca de três ou mais semanas após o nascimento começam a desenvolver sinais clínicos (DUBEY et al., 2007b), como paralisia dos membros posteriores seguida de evolução para uma paralisia progressiva. A sintomatologia neurológica depende do local parasitado, sendo que os membros posteriores são comumente mais acometidos quando comparados aos anteriores, condição esta que não impede que o animal mantenha-se alerta, podendo sobreviver por meses. O cão infectado também pode apresentar dificuldade na deglutição, paralisia da mandíbula, flacidez e atrofia muscular, bem como insuficiência cardíaca (DUBEY, 2003).

Dados relativos à epidemiologia vêm sendo investigado em diferentes regiões do Brasil (AZEVEDO et al., 2005; CAÑÓN-FRANCO et al., 2003; FERNANDES et al., 2004; GENNARI et al., 2002; PLUGGE et al., 2011). No estado de Mato Grosso, anticorpos contra N. caninum foram averiguados na espécie canina na cidade de Cuiabá com ocorrência de anticorpos variando de 45 a $67,6 \%$ em cães atendidos em hospital veterinário, e oriundos de fazendas, respectivamente (BENETTI et al., 2008; BENETTI et al., 2009). Diante da importância da espécie canina no ciclo biológico do $N$. caninum e de recentes relatos apontando para a sua ocorrência no Estado de Mato Grosso, o presente estudo teve como objetivos investigar a prevalência de anticorpos anti- $N$. caninum em cães de Cuiabá, assim como, associar a positividade a possíveis riscos para sua ocorrência.

\section{Material e Métodos}

Entre os meses de dezembro de 2008 a dezembro de 2009 foram obtidas amostras de soro de cães domiciliados na área urbana do município de Cuiabá $\left(15^{\circ} 35^{\prime} 56^{\prime}\right.$ 'S e $\left.56^{\circ} 06^{\prime} 01^{\prime \prime O}\right)$. Para obter o número de amostras, utilizou-se o total da população canina na cidade de Cuiabá (estipulada pelo Centro de Controle de Zoonoses em 2007) de 96.504 cães, considerando prevalência esperada de $10 \%$, erro estatístico de $3 \%$ e intervalo de confiança de $95 \%$ com auxilio do programa Epiinfo 3.5.3. A partir desse cálculo, o número mínimo de amostras seria de 386 animais, mas para abranger um número maior de residências optou-se por coletar 406 cães. As coletas foram realizadas de forma aleatória envolvendo as quatro regiões administrativas de Cuiabá, regiões Norte, Sul, Leste e Oeste.

Os soros foram testados pela Reação de Imunofluorescência Indireta (RIFI) empregando-se como antígenos, taquizoítos da cepa NC-Bahia de $N$. caninum cultivados em células VERO, com ponto de corte na diluição inicial de 1:50 (AGUIAR et al., 2006). Em todas as reações foi utilizado conjugado anti-IgG de cão (Sigma, St. Louis, MO) na diluição de 1:1000. Em cada lâmina, uma amostra sorológica negativa e outra positiva foram utilizadas na diluição 
de 1:50. As reações consideradas positivas para $N$. caninum na análise qualitativa foram submetidas ao teste quantitativo, em que diluições na razão dois possibilitaram determinar o título final.

Durante a coleta de sangue aplicou-se questionário com os proprietários ou residentes com intuito de se observar possíveis associações com a presença de anticorpos nos cães. As variáveis abordaram questões relativas à caracterização dos cães (sexo, raça e idade), comportamento e ambiente (acesso a rua, local de moradia, presença de roedores e hábitos alimentares). O Teste do Quiquadrado $\left(\chi^{2}\right)$ ou Exato de Fisher foi utilizado para avaliar possíveis associações, sendo considerado significativo a variável que apresentasse o valor de $\mathrm{P}<0,05$. Para estes cálculos utilizou-se o programa estatístico EPIINFO 3.5.3 para Windows.

\section{Resultados e Discussão}

Foram detectados 27 (6,6\%; IC95\%: 4,5-9,6) cães soropositivos para $N$. caninum, com títulos variando entre 50 e 1600 (Tabela 1). De acordo com a bibliografia consultada, o valor da prevalência $(6,6 \%)$ de anticorpos anti- $N$. caninum em cães no presente estudo está entre as mais baixas do Brasil. O resultado contrasta com resultado anterior relatado por Benetti et al. $(2008 ; 2009)$ em Cuiabá, que verificaram a ocorrência de anticorpos anti- $N$. caninum em 45\% (27/60) de cães atendidos em hospital veterinário. Deve-se considerar a metodologia amostral empregada no presente estudo que avaliou de forma aleatória a população canina da cidade de Cuiabá, analisando cães de todas as regiões da cidade. No estudo anterior, foram avaliados cães atendidos em hospital veterinário, muitos provenientes de áreas rurais ou de bairros próximos. Vários autores vêm afirmando que cães oriundos de áreas rurais ou com contato frequente com esse meio ambiente apresentam maiores frequências de anticorpos quando comparados às de áreas urbanas (AGUIAR et al., 2006; CAÑÓNFRANCO et al., 2003; FERNANDES et al., 2004; FRIDLUND-PLUGGE et al., 2008), o que é justificado pelo maior contato dos cães com espécies que podem desempenhar papel de hospedeiros intermediários (DIJKSTRA et al., 2001).

Tabela 1. Número e frequência de cães reagentes à Reação de Imunofluorescência Indireta para Neospora caninum segundo faixa etária e título de anticorpos. Cuiabá, 2011.

\begin{tabular}{ccccccccc}
\hline \multirow{2}{*}{$\begin{array}{c}\text { Faixa etária } \\
\text { (meses) }\end{array}$} & $\begin{array}{c}\text { Número de cães } \\
\text { Testados }\end{array}$ & $\begin{array}{c}\text { Número de cães } \\
\text { positivos (\%)* }\end{array}$ & \multicolumn{7}{c}{ Títulos de anticorpos (\%) } \\
\hline 0 a 12 & 68 & $2(0,49)$ & 1 & 0 & 0 & 0 & 0 & 1 \\
$>$ 12 a 24 & 70 & $2(0,49)$ & 0 & 1 & 0 & 1 & 0 & 0 \\
>24 a 48 & 90 & $7(1,71)$ & 3 & 3 & 0 & 1 & 0 & 0 \\
>48 a 72 & 80 & $6(1,47)$ & 1 & 1 & 1 & 2 & 1 & 0 \\
>72 & 76 & $7(1,71)$ & 1 & 2 & 2 & 1 & 1 & 0 \\
Indeterminada & 22 & $3(0,73)$ & 0 & 0 & 0 & 2 & 1 & 0 \\
\hline Total & 406 & $26(6,7)$ & $6(22,2)$ & $7(25,9)$ & $3(11,1)$ & $7(25,9)$ & $3(11,1)$ & $1(3,8)$ \\
\hline
\end{tabular}

$* \mathrm{P}>0,05$

Fonte: Elaboração dos autores. 
Não houve associações significativas entre as variáveis analisadas pelo teste do $\chi^{2}$ ou Exato de Fisher e os resultados da sorologia para $N$. caninum. Ao que se refere à raça dos cães estudados, apesar da ausência de associação entre essa variável e a presença de anticorpos anti- $N$. caninum, a maioria dos casos soropositivos foram descritos em Labrador Retriever, Boxer, Greyhound, Golden Retriever e Basset Hound. No presente estudo, quatro cães $(16,7 \%)$ da raça Pit Bull foram positivos e apresentaram $\mathrm{P}=0,06$, próximo a margem de significância estatística (Tabela 2). Dos 24 cães da raça Pit Bull avaliados, todos habitavam casas com muro, entretanto $10(41 \%)$ tinham acesso à rua, e destes, três $(30,0 \%)$ foram positivos (dados não apresentados). Apesar disso, se há predisposição racial para esta infecção trata-se de algo até então desconhecido (DUBEY, 2003). Não foi observada diferenças entre a proporção de cães positivos em relação à idade (Tabela 1). Este resultado contrasta achados de outros trabalhos, que têm observado a maior frequência de reações positivas em cães de idade avançada, justificado pelo maior tempo de exposição ao agente (SOUZA et al., 2002; CAÑÓNFRANCO et al., 2003).

Tabela 2. Frequência de anticorpos anti-Neospora caninum segundo a raça dos cães avaliados na cidade de Cuiabá, MT.

\begin{tabular}{lccc}
\hline \multirow{2}{*}{ Raça } & \multicolumn{3}{c}{ Número de cães } \\
\cline { 2 - 4 } & Avaliados $(\%)$ & Positivos $(\%)$ & 0,17 \\
\hline Indefinida & $267(65,8)$ & $14(5,2)$ & 0,06 \\
Pit Bull & $24(5,9)$ & $4(16,7)$ & 0,39 \\
Boxer & $20(4,9)$ & $2(10,0)$ & 0,60 \\
Poodle & $20(4,9)$ & $1(5,0)$ & 0,28 \\
Teckel & $16(3,9)$ & $2(12,5)$ & 0,40 \\
Rottweiler & $13(3,2)$ & 0 & 0,42 \\
Pinscher & $8(2,0)$ & $1(12,5)$ & 0,38 \\
Pastor Alemão & $1(14,3)$ & 0,61 \\
Labrador Retriever & $7(1,7)$ & 0 & 0,29 \\
Fila Brasileiro & $7(1,7)$ & $1(20,0)$ & 0,75 \\
Dálmata & $5(1,2)$ & 0 & 0,12 \\
Dobermann & $4(1,0)$ & $1(50,0)$ & 0,87 \\
Shih Tzu & $2(0,5)$ & 0 & 0,87 \\
Shar Pei & $2(0,5)$ & 0 & 0,87 \\
Pastor Belga & $2(0,5)$ & 0 & 0,93 \\
Outros* & $2(0,5)$ & 0 & \\
\hline
\end{tabular}

* Basset Hound, Weimaraner, Lhasa Apso, Terrier brasileiro, Cocker Spaniel, Chow Chow e Beagle.

Fonte: Elaboração dos autores.

$\mathrm{Na}$ tabela 3 estão apresentados os resultados do teste de associação. Em relação ao sexo, também não houve associação com a presença de anticorpos nos cães, estando tanto machos como fêmeas na mesma proporção de positivos, resultado similar ao encontrado anteriormente por Benetti et al. (2008). Cães que habitam casas sem muro ou casas próximas a terrenos baldios apresentaram frequências de $8,5 \%$ e $7,1 \%$ respectivamente, porém sem associação significativa. A ausência de associação aponta para a baixa contaminação ambiental por N. caninum. Pelos resultados do presente estudo, a presença de roedores nas residências de 294 cães, também não foi associada à ocorrência de cães 
soropositivos. Dentre as possíveis opções de caça para cães urbanos, estão os roedores, que já foram citados como potenciais hospedeiros intermediários (DUBEY; SCHARES; ORTEGA-MORA, 2007a). Collantes-Fernandez et al. (2008) na Espanha, concluíram que o tipo de dieta pode influenciar na soropositividade dos animais avaliados, pois cães com habito de caça representam uma população de risco para infecção pelo protozoário. Entretanto, os valores de soroprevalência foram similares em cães que recebiam diferentes tipos de alimentos (ração ou mista). Sabe-se que tecidos de qualquer animal que contenham cistos podem ser uma fonte de infecção para cães (DUBEY; SCHARES, 2011). Por outro lado, a característica da dieta oferecida ao cão pode, em determinadas circunstâncias, influenciar o comportamento canino, principalmente daqueles com acesso à rua, pois estes animais possuem maiores chances de ingerir uma grande variedade de alimentos inclusive a caça. Sobre o acesso à rua, esta não foi associado a presença de anticorpos anti- $N$. caninum, concordando com os resultados de Fridlund-Plugge et al. (2008) em Curitiba, PR, de que o acesso a rua não predispõe à infecção por $N$. caninum. Porém, relatos anteriores de Azevedo et al. (2005) em Campina Grande, PB, Gennari et al. (2002) em São Paulo, SP, e Benetti et al. (2008) em Cuiabá verificaram esta associação.

Tabela 3. Frequência de anticorpos anti-Neospora caninum em cães da cidade de Cuiabá, MT e análise de associação com diferentes variáveis estudadas.

\begin{tabular}{|c|c|c|c|}
\hline \multirow{2}{*}{ Variáveis analisadas } & \multicolumn{3}{|c|}{ Número de cães } \\
\hline & Analisados (\%) & Positivos (\%) & $P$ \\
\hline \multicolumn{4}{|l|}{ Sexo } \\
\hline Fêmea & $180(44,4)$ & $10(5,6)$ & \\
\hline Macho & $226(55,5)$ & $17(7,5)$ & 0,55 \\
\hline \multicolumn{4}{|l|}{ Alimentação } \\
\hline Ração & $78(19,2)$ & $7(9,0)$ & \\
\hline Mista & $328(80,8)$ & $20(6,1)$ & 0,50 \\
\hline \multicolumn{4}{|l|}{ Acesso à rua } \\
\hline Sim & $200(49,3)$ & $15(7,5)$ & \\
\hline Não & $206(50,7)$ & $12(5,8)$ & 0,63 \\
\hline \multicolumn{4}{|c|}{ Casas próximas a terrenos baldios } \\
\hline $\operatorname{Sim}$ & $296(72,9)$ & $21(7,1)$ & \\
\hline Não & $110(27,1)$ & $6(5,5)$ & 0,71 \\
\hline \multicolumn{4}{|l|}{ Roedores no ambiente } \\
\hline Sim & $294(72,4)$ & $20(6,8)$ & \\
\hline Não & $112(27,6)$ & $7(6,3)$ & 0,98 \\
\hline \multicolumn{4}{|l|}{ Casa com muro } \\
\hline Sim & $324(79,8)$ & $20(6,2)$ & \\
\hline Não & $82(20,2)$ & $7(8,5)$ & 0,60 \\
\hline
\end{tabular}

Fonte: Elaboração dos autores. 
Concluímos no presente estudo que a prevalência de anticorpos anti- $N$. caninum na população canina é baixa e as diversas variáveis estudadas não se apresentaram associadas à infecção. Ressalta-se a menor prevalência da infecção nas áreas urbanas do Brasil.

\section{Agradecimentos}

Aos graduandos em medicina veterinária Rute Witter e Thábata dos Anjos Pacheco pela formatação do banco de dados. À Coordenação de Aperfeiçoamento de Pessoal de Nível Superior (CAPES) e à Fundação de Amparo à Pesquisa do Estado de Mato Grosso (FAPEMAT) pelas bolsas de mestrado de A.L.T. Melo e G.P.C. Silva.

\section{Comitê de Ética e Biossegurança}

Aprovado pelo Comitê de Ética em Pesquisa Animal da Universidade Federal de Mato Grosso sob o número 23108.040913/08-2.

\section{Referências}

AGUIAR, D. M.; CAVALCANTE, G. T.; RODRIGUES, A. A. R.; LABRUNA, M. B.; CAMARGO, L. M. A.; CAMARGO, E. P.; GENNARI, S. M. Prevalence of anti-Neospora caninum antibodies in cattle and dogs from Western Amazon, Brazil, in association with some possible risk factors. Veterinary Parasitology, Amsterdam, v. 142, n. 1, p. 71-77, 2006.

AZEVEDO, S.S.;BATISTA, C.S.A.;VASCONCELLOS, S. A.; AGUIAR, D. M.; RAGOZO, A. M. A.; RODRIGUES, A. A. R.; ALVES, C. J.; GENNARI, S. M. Seroepidemiology of Toxoplasma gondii and Neospora caninum in dogs from the state of Paraíba, Northeast region of Brazil. Research in Veterinary Science, EUA, v. 79, n. 1, p. 51-56, 2005.

BENETTI, A. H., SCHEIN, F. B.; SANTOS, T. R.; TONIOLLO, G. H.; COSTA, A. J.; MINEO, J. R.; LOBATO, J.; SILVA, D. A. O.; GENNARI, S. M. Pesquisa de anticorpos anti-Neospora caninum em bovinos leiteiros, cães e trabalhadores rurais. Revista Brasileira de Parasitologia Veterinária, São Paulo, v. 18, p. 29-33, 2009. Suplemento 1.
BENETTI, A. H.; TONIOLlO, G. H.; SANTOS, T. R.; GENNARI, S. M.; COSTA, A. J.; DIAS, R. A. Ocorrência de anticorpos anti-Neospora caninum em cães no município de Cuiabá, Mato Grosso. Ciência Animal Brasileira, Goiânia, v. 9, n. 1, p. 177-180, 2008.

CAÑÓN-FRANCO, W. A.; BERGAMASCHI, D. P.; LABRUNA, M. B.; CAMARGO, L. M. A.; SOUZA, S. L. P.; SILVA, J. C. R.; PINTER, A.; DUBEY, J. P.; GENNARI, S. M. Prevalence of antibodies to antiNeospora caninum in dogs from Amazon, Brazil. Veterinary Parasitology, Amsterdam, v. 115, n. 1, p. 7174, 2003.

COLLANTES-FERNÁNDEZ,E.; GÓMEZ-BAUTISTA, M.; MIRÓ, G.; ÁlVAREZ-GARCÍA, A.; PEREIRABUENO, J.; FRISUELOS, C.; ORTEGA-MORA, L. M. Seroprevalence and risk factors associated with Neospora caninum infection in different dog populations in Spain. Veterinary Parasitology, Amsterdam, v. 152, n. 1. p. $148-151,2008$.

DIJKSTRA, T. H.; EYSKER, M.; SCHARES, G.; CONRATHS, F. J.; WOUDA, W.; BARKEMA, H. W. Dogs shed Neospora caninum oocyst after ingestion of naturally infected bovine placenta but not after ingestion of colostrum spiked with Neospora caninum tachyzoites. International Journal of Parasitology, Elmsford, v. 31, n. 8, p. 747-752, 2001.

DUBEY, J. P. Review of Neospora caninum and neosporosis in animals. Korean Journal of Parasitology, Seoul, v. 41, n. 1, p. 1-16, 2003.

DUBEY, J. P.; SCHARES, G. Neosporosis in animals the last five years. Veterinary Parasitology, Amsterdam, v. 180 , n. 1, p. 90-108, 2011.

DUBEY, J. P.; SCHARES, G.; ORTEGA-MORA, L. M. Epidemiology and Control of Neosporosis and Neospora caninum. Clinical Microbiology Review, Washington, v. 20, n. 2, p. 323-367, 2007 a.

DUBEY, J. P.; VIANNA, M. C. B.; KWOK , O. C. H.; HILL, D. E.; MISKA, K. B.; TUO, W.; VELMURUGAN, G. V.; CONORS, M.; JENKINS, M. C. Neosporosis in Beagle dogs: clinical signs, diagnosis, treatment, isolation and genetic characterization of Neospora caninum. Veterinary Parasitology, Amsterdam, v. 149, n. 3, p.158-166, 2007b.

FERNANDES, B. C. T. M.; GENNARI, S. M.; SOUZA, S. L. P.; CARVALHO, J. M.; OLIVEIRA, W. G.; CURY, M. C. Prevalence of anti-Neospora caninum antibodies in dogs from urban, periurban and rural areas of the city of Uberlândia, Minas Gerais - Brazil. Veterinary Parasitology, Amsterdam, v. 123, n. 1, p. 33-40, 2004. 
FRIDLUND-PLUGGE，N.; MONTIANI-FERREIRA, F.; RICHARTZ, R. R. T. B.; PIZZOL, J. D.; MACHADO, P. C. JR.; PATRÍCIO, L. F. L.; ROSINELLI, A. S.; LOCATELLI-DITTRICH, R. Frequency of antibodies against Neospora caninum in stray and domiciled dogs from urban, periurban and rural areas from Paraná state, Southern Brazil. Revista Brasileira de Parasitologia Veterinária, São Paulo, v. 17, n. 4, p. 222-226, 2008.

GENNARI, S. M.; YAI, L. E. O.; D’ÁURIA, S. N. R.; CARDOSO, S. M. S.; KWOK, O. C. H.; JENKINS, M. C.; DUBEY, J. P. Occurrence of Neospora caninum antibodies in sera from dogs of the city of São Paulo, Brazil. Veterinary Parasitology, Amsterdam, v. 106, n. 2, p. 177-179, 2002.

GONDIM, L. F. P.; MCALLISTER, M. M.; PITT, W. C.; ZEMLICKA, D. E. Coyotes (Canis latrans) are definitive hosts of Neospora caninum. International Journal of Parasitology, Elmsford, v. 34, n. 2, p. 159-161, 2004.
KING, J. S.; SLAPETA, J.; JENKINS, D. J.; ALQASSAB, S. E.; ELLIS, J. T.; WINDSOR, P. A. Australian dingoes are definitive hosts of Neospora caninum. International Journal of Parasitology, Elmsford, v. 40, n. 8, p. 945-950, 2010.

MCALLISTER, M. M.; DUBEY, J. P.; LINDSAY, D. S.; JOLLEY, W. R.; WILLS, R. A.; MCGUIRE, A. M. Dogs are definitive hosts of Neospora caninum. International Journal of Parasitology, Elmsford, v. 28, n. 9, p. 14731478, 1998.

PLUGGE, N. F.; FERREIRA, F. M.; RICHARTZ, R. R. T. B.; SIQUEIRA, A.; LOCATELLI-DITTRICH, R. Occurrence of antibodies against Neospora caninum and/ or Toxoplasma gondii in dogs with neurological signs. Revista Brasileira de Parasitologia Veterinária, São Paulo, v. 20, n. 3, p. 202-206, 2011.

SOUZA, S. L. P.; GUIMARÃES JUNIOR, J. S.; FERREIRA, F.; DUBEY, J. P.; GENNARI, S. M. Prevalence of Neospora caninum antibodies in dogs from dairy cattle farms in Paraná, Brazil. The Journal of Parasitology, Richmond, v. 88, n. 2, p. 408-409, 2002. 
